\title{
Fabrication and Characterization of Silicon-Based Solar Cell Using Keithley 2400 SMU
}

\author{
Hafeez Y. Hafeez ${ }^{1}$,Zaharaddeen S. Iro ${ }^{2}$, Ibrahim Saadu ${ }^{3}$ and Bala I. Adam ${ }^{4}$ \\ ${ }^{134}$ Physics Department, Federal University Dutse P.M.B 7156, Jigawa State- Nigeria. \\ ${ }^{2}$ Department of Electrical and Electronics, SRM University, Kattankulathur - 603203,Tamil Nadu, India. \\ Corresponding Author: hafeezyusufhafeez@gmail.com, +2348064706870.
}

\begin{abstract}
Silicon remains the material of choice for photovoltaic because of its abundance, non-toxicity, high and stable cellefficiencies. In this paper, we fabricate and characterize a silicon-based solar cell device and estimated important parameters of the device such as Open Circuit Voltage $V_{o c}$ of $0.57 \mathrm{~V}$, Short-Circuit Current $I_{s c}$ of $2.5 \times 10^{-5} \mathrm{~A}$, Maximum Power $P_{\max }$ of $6 \times 10^{-6} \mathrm{~W}$, Fill Factor of 0.421 and the energy conversion efficiency of $\eta=0.006 \%$ were tested using Keithley 2400, source meter under A.M $1.5\left(1000 / \mathrm{m}^{2}\right)$ illumination from a Newport Class A solar simulator. Also the I-V characteristics were drawn in both dark and light illuminations.
\end{abstract}

Keywords: Solar cell, Fill factor, efficiency, silicon, Indium Tin-oxide

\section{Introduction}

The fabrication of solar cells that is based on the technology of crystalline silicon is increasing. The pioneering work by Albert Einstein in 1905 on the photoelectric effect provided the fundamental basis for the development of solar cells. The silicon-based photovoltaic (solar cell) is based largely on the p- and n-doped silicon's that are arranged into $\mathrm{p}-\mathrm{n}$ junctions that are connected in series and parallel.

Silicon-based solar cells are the current building block in photovoltaic. They are from silicon wafers whose surfaces have been treated to maximize light absorption. Whenever radiation from the sun hits a silicon solar cell, it generates current. Silicon solar cells are based on p-n junction that produces electron in the p-type region and holes in the n-type region. This lowers the potential energy barrier at the junction. Hence, a current flows and establishes an external potential. The current produced by a solar cell is usually too low for most applications; hence, many cells are connected in series-parallel to produce a module with a substantial output. Many methods have been proposed to improve solar-cell efficiency, including metal wrap through (MWT)Solar cell [1,2], emitter wrap through (EWT) cells [3,4], interdigitated backside contact (IBC) cells[5,6], laser-fired contacts cells [7,8], and ion-implanted cells [9,10]. Many of these methods, ionimplantation is an attractive and cost-effective process. Although nowadays an efficiency of the thin film cells islower than Monocrystalline silicon cells, it is expected that in thefuture production on a massive scale will be much cheaper. Currently, the most advanced thin film cells are made ofamorphous silicon (a-Si) its alloys (a-SiGe, a-SiC). Thin film cells have achieved efficiency of $13 \%$ in the laboratory scale. Amorphous silicon cells are commonly use in products requiringlow power supply (pocket calculators, watches, etc.) [11,12].Monocrystalline solar cells show the highest conversionefficiency of all silicon solar cells, but the product Monocrystalline silicon wafers requires the largest investmentfunds. In laboratory studies single solar cell efficiency reaches the order of $24 \%$. Solar cells produced on a mass scale haveofefficiency of around 17\% [12-13].Polycrystalline silicon solar cells are made of large blockssilicon. They are produced in special crucibles, which slowlycool down the molten silicon to make the growof polycrystalline with large grains. Next blocks are cut on the waferby sawing. Polycrystalline cells are less efficient thanMonocrystalline, but their production cost is lower due to the skip of energy-intensive manufacturing single crystal [12-14].

Some important solar cell characteristics can be obtained from simple I-V curves. The short circuit current $\left(I_{\mathrm{sc}}\right)$ is the current through the solar cell when the voltage across the solar cell is zero. The open circuit voltage $\left(\mathrm{V}_{\mathrm{oc}}\right)$ is the voltage across the solar cell when the current through the solar cell is zero and it is the maximum voltage available from the solar cell. The maximum power point $\left(\mathrm{P}_{\max }\right)$ is the condition under which the solar cell generates its maximum power; the current and voltage in this condition are defined as $I_{\max }$ and $V_{\max }$ (respectively). The fill factor (FF) equation (1) and the energy conversion efficiency ( $\eta$ ) equation (2) are metrics used to characterize the performance of the solar cell. The fill factor is defined as the ratio of $\mathrm{P}_{\max }$ divided by the product of $\mathrm{V}_{\mathrm{oc}}$ and $\mathrm{I}_{\mathrm{sc}}$. The conversion efficiency is defined as the ratio of $\mathrm{P}_{\max }$ to the product of the input light irradiance $(E)$ and the solar cell surface area $A_{c}$ [15].

$$
F F=\frac{P_{\max }}{V_{o c} \times I_{s c}}
$$




$$
\eta=\frac{V_{o c} \times I_{S c} \times F F}{E \times A_{c}}
$$

In this article, The I-V characteristics of Silicon Based Solar Cell were obtained using a keithley 2400 source meter under A.M $1.5\left(100 \mathrm{Mw} / \mathrm{cm}^{2}\right)$ illumination from a Newport class A solar simulator (SHESTCO, Abuja) and finally the important parameters were executed according to equation (1) and (2).

\subsection{A Typical P-N Junction Solar Cell}

Atypical silicon solar cell is essentially a p-n junction diode. To optimize its performance, the following are usually done:

- Including a thin intrinsic buffer layer between the $\mathrm{n}-\mathrm{Si}$ and the $\mathrm{p}$ - layers.

- Improving the Ohmic back contact by depositing an $\mathrm{n}+$ microcrystalline layer on the back of $\mathrm{n}-\mathrm{Si}$ prior to the aluminium contact.

- Using an antireflective layer (such as ITO) on top of p-Si layer prior to the silver grid (contact).

The resulting high efficiency silicon hetero-junction solar cell is therefore $\mathrm{Ag} / \mathrm{ITO} / \mathrm{p}-\mathrm{Si} / \mathrm{i}-\mathrm{Si} / \mathrm{n}$ $\mathrm{cSi} / \mathrm{n}+\mathrm{ucSi} / \mathrm{Al}$ as shown below in Fig $\mathbf{1}$.

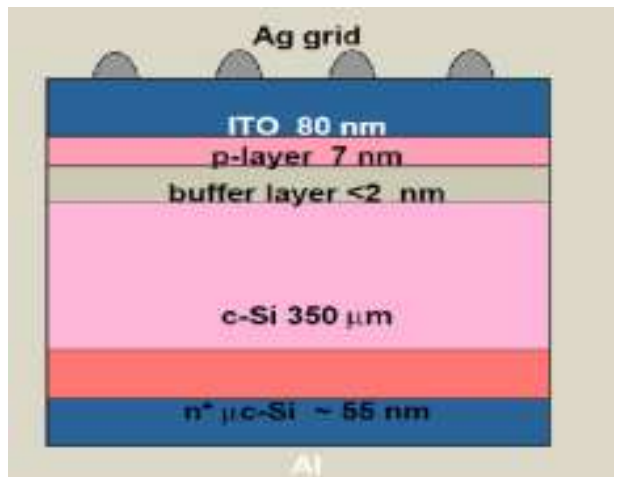

Fig 1: An Example of High Efficiency Si Hetero-Junction Solar Cell Device

\section{Experimental Detail And Materials}

Hydrogen Fluoride (HF) (1\% volume concentration), Nitrogen gas, pure aluminum rod (99.9\%) of about length $15 \mathrm{~mm}$ and radius $1 \mathrm{~mm}$, isopropanol, ethanol, p-Si wafer of $1 \times 1 \mathrm{~cm}^{2}$, Indium tin oxide (ITO), Edwards Auto 306 Thermal Evaporator, Furnace, Infinicon Thin Film Controller, Newport Oriel Instruments Model 65194A-100 Solar Simulator,Adventurer OHAUS AR2740 digital weighing machine, 2 Digital DT9205A Multi-meters, voltmeter (EDM-14, 0-2V), ammeter (EDM-14, -20-100 $\mu$ A). All these materials are analytical grade and used as received without any further purification

\subsection{The Keithley Series 2400 Source Measure Unit}

A common laboratory method of characterizing the current-voltage characteristics of solar cells is to use a parameter analyzer that employs measurement ports known as Source-Measurement Units (SMUs). In order to measure the current-voltage characteristics of the solar cell, the SMU typically is stepped through various voltage limiting levels and the corresponding currents are measured. The Keithley's Series 2400 Source Meter instruments are widely used for solar cell production testing because they enable test engineers to configure a test system using a single instrument that can source and measure both current and voltage. 


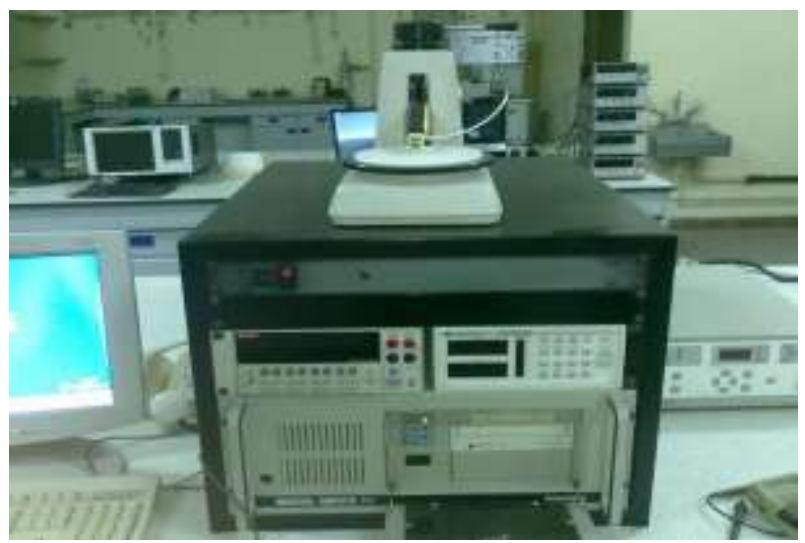

Fig 2: Keithley 2400 SMU for I - V Characterization (SHESTCO, Abuja)

\subsection{Fabrication of the Silicon-Based Solar Cell}

\subsubsection{Cutting and Etching of the Silicon wafer}

First, the table used was cleaned with ethanol and a clean cloth was placed on it. Then, the silicon wafer was brought out from its pack and cut into two across its diameter. The properties of the silicon wafer used were as follows; 2" silicon wafer, Type/Dopant: P/Boron, Orientation: <111>, Diameter: $50.8 \mathrm{~mm}$, Thickness: $27525 \mu \mathrm{m}$, Resistivity: $0.1-10 \mathrm{ohm}-\mathrm{cm}$, Surface: one sided polished. The surface of the cut p-Si wafer was then rinsed carefully in de-ionized water and etched with Hydrogen Fluoride (HF) $[1 \%$ volume concentration] by dipping it into it for 1 minute, after which it was blow-dried using Nitrogen gas from a Nitrogen gun. The blow-dried p-Si was then placed on a mask in the enclosed casing of the sputtering machine.

\subsubsection{Deposition of Indium Tin-oxide by Sputtering and Annealing}

Indium Tin-oxide (ITO) was sputtered unto the etched p-Si wafer (placed on a shadow mask of $1 \times 1 \mathrm{~cm}^{2}$, with the polished side facing downwards) and then put into the sputtering chamber of an Edwards Auto $306 \mathrm{RF}$ magnetron sputtering system that was operated at an initial vacuum pressure of $4.0 \times 10^{-5}$ Torr and rf power of 40 $\mathrm{W}$. This was done by pressing the 'cycle' button to create vacuum in the chamber until a fine pumping is attained. Two cups of nitrogen gas were poured into the sputtering system gas chamber to facilitate the vacuum creation. The sputtering was carried out at room-temperature. Argon, which was the sputtering gas, was introduced into the chamber to excite ions on the ITO target. The rf generator supplied the required power across the target to the substrate in the system, thereby creating the Argon plasma needed for the sputtering process to begin. A nominal thickness of $200 \mathrm{~nm}$ of ITO was coated onto the glass after about 1 hour, 8minutes. The thickness was carefully monitored by observing the thickness monitor. Once the desired thickness was attained, the shutter was closed, the rf generator turned off and the sputtering gas supply was closed. Subsequently, the ITO coated p-Si samples were annealed at $250^{\circ} \mathrm{C}$ for 1 hour.

\subsubsection{Evaporation of Aluminum Back Contact by Thermal Vacuum Evaporation}

Finally, an aluminum cathode layer was evaporated behind the sputtered and annealed p-Si samples by thermal vacuum evaporation. This was done by inserting a pure aluminum rod (99.9\%) of about length $15 \mathrm{~mm}$ and radius $1 \mathrm{~mm}$, which was striated, on a tungsten filament in the evaporation chamber of the Edwards Auto 306 Thermal Evaporator. This was melted in a high vacuum $\left(2.0 \times 10^{-5}\right.$ Torr $)$ environment. Rate of deposition and thickness was controlled using the Infinicon Thin Film Controller. The aluminum was then evaporated and coated through a shadow mask behind the ITO/p-Si so as to obtain the cathode back contact. This was then taken for I-V characterization.

\section{I-V Measurement}

The silicon-based solar cell (DUT) was connected to the Keithley 2400 SMU. The red clips were connected to the ITO anode, while the black clips to the aluminum cathode. The experiment was verified to ensure all connections were right before the source measure unit was switched on. The SMU was switched on (while the solar simulator was kept OFF). The experiment was programmed to source the voltage from $0-0.7 \mathrm{~V}$ with a step- size of $0.05 \mathrm{~V}$ with the aid Labtracer software. The current-voltage values were measured. This was done to obtain the dark I - V characterization of our DUT. The solar simulator was afterward switched on and with the aid Labtracer software, the experiment was programmed to source the voltage from $0-0.7 \mathrm{~V}$ with a step- size of $0.05 \mathrm{~V}$. The current was as well measured. This was done to obtain the I - V characterization under dark and illumination.

IV. Results And Discussion

The I -V characteristics for both dark and light were plotted as shown below in Fig 2. 


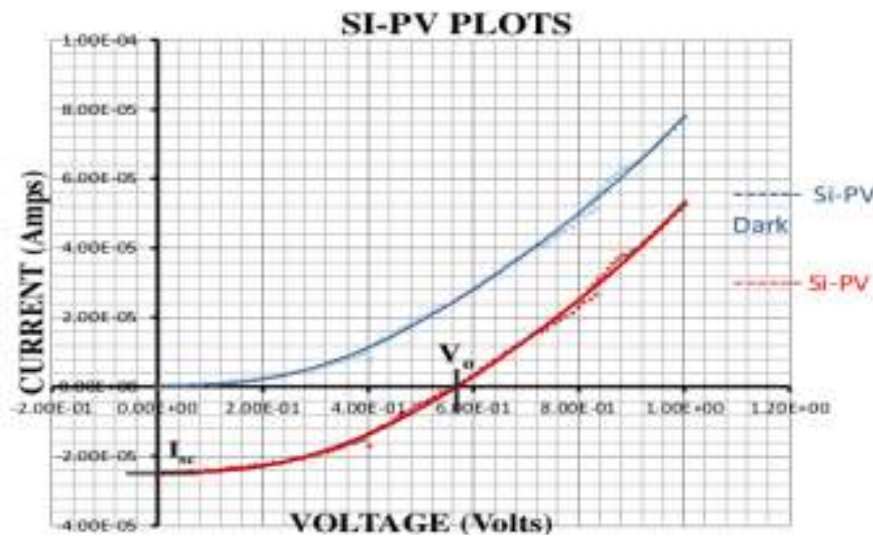

Fig 2: Graph of Current versus Voltage for the Si-PV device Characterization

Considering the Light I-V graph, we can clearly see that the Open Circuit Voltage, $\mathrm{V}_{\mathrm{oc}}$, (which is the voltage applied when the current applied is zero) is $5.7 \times 10^{-1}$ Volts.

The Short Circuit Current, $\mathrm{I}_{\mathrm{sc}}$, which is the current when the applied voltage is zero, is obtained as

$2.5 \times 10^{-5}$ Amps. Maximum Power, $P_{\max }$, which is the product of maximum current $\left(\mathrm{I}_{\max }\right)$ and the maximum voltage $\left(\mathrm{V}_{\max }\right)$ can be obtained from the given result data (Current - voltage data) by first obtaining the power values for each given current - voltage datum, since power $=$ current $\mathrm{x}$ voltage. This was then plotted against the given voltage as shown below in Fig $3 \& 4$ to obtain the maximum power, $\mathrm{P}_{\max }$, and subsequently, the corresponding $\mathrm{V}_{\max }$ was obtained, as well as the $\mathrm{I}_{\max }$.

\section{Power Vs Voltage Plot of Si-PV}

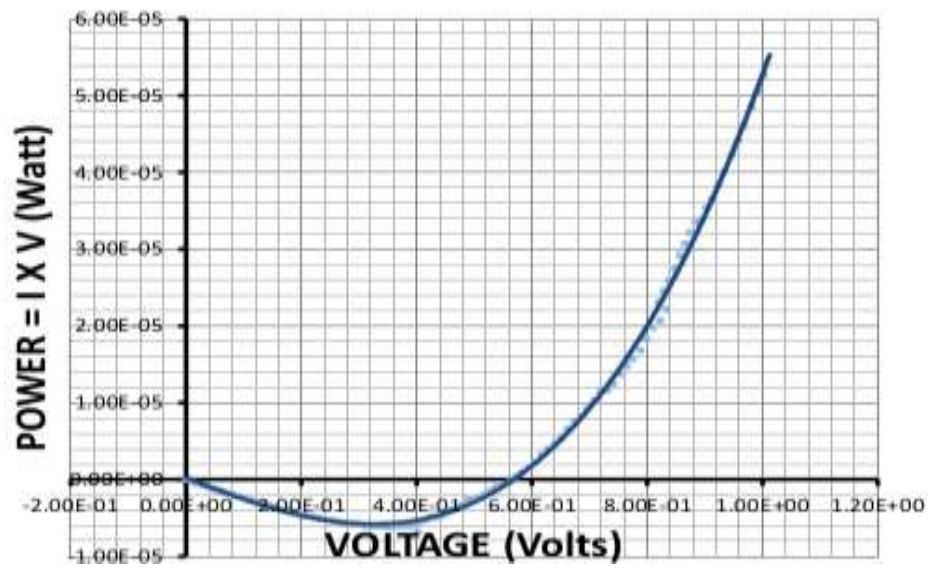

Fig 3: Graph of Power versus Voltage of the OPV Device

The graph of power against voltage was also plotted to read the $P_{\max }$ and corresponding $V_{\max }$, in Fig 4 .

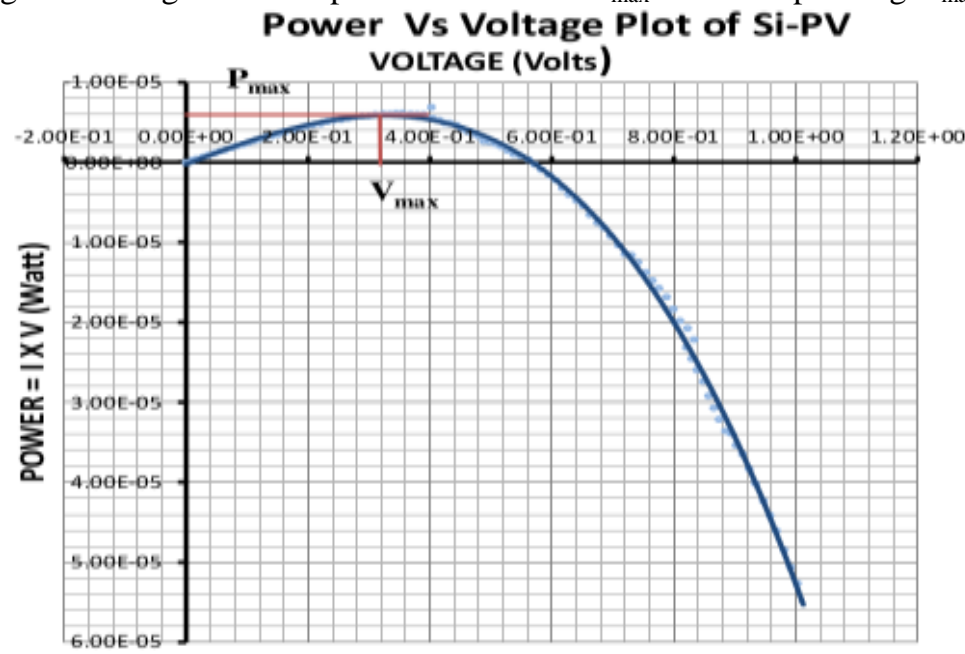

Fig 4: Graph of Power versus Voltage of the Si-PV Device 
From Fig 4, the Maximum Power of the OPV device is $0.6 \times 10^{-5}$ Watts $=6 \times 10^{-6}$ Watts correspond to the maximum voltage $V_{\max }=3.2 \times 10^{-1}$ Volts , Thus

$$
I_{\max }=\frac{P_{\max }}{V_{\max }}=\frac{6 \times 10^{-6}}{3.2 \times 10^{-1}}=1.875 \times 10^{-5} \text { Amps }
$$

The fill factor, energy conversion efficiency according to equation (2) and (1)[16] are

$$
\text { FillFactor }(F F)=\frac{P_{\max }}{V_{O C} \times I_{S C}}=\frac{6 \times 10^{-6}}{0.57 \times 2.5 \times 10^{-5}}=0.421
$$

The surface area of solar cell $A_{c}$ is $1 \times 1 \mathrm{~cm}^{2}=1 \mathrm{~cm}^{2}=10^{-4} \mathrm{~m}^{2}$ with conversion efficiency of

$$
\eta=\frac{V_{O C} \times I_{S C} \times F F}{E \times A_{c}}=\frac{0.57 \times 2.5 \times 10^{-5} \times 0.421}{1000 \times 10^{-4}}=0.006
$$

\section{Conclusion}

Based on the measured current - voltage characteristics of silicon solar cell, the solar module were used to build silicon solar cell with open circuit voltage of $0.57 \mathrm{~V}$ and short circuit current of $2.5 \times 10^{-5} \mathrm{~A}$. Also, the Fill Factor 0.421, which is a measure of how good and effective a solar cell is as it tends to 1.0 was calculated, and it revealed that our fabricated silicon-based solar cell device is a fairly good one. Hopefully, in subsequent works, we will optimize our experiments so as to obtain a higher FF value. Also the efficiency of $0.006 \%$ was achieved.

\section{References}

[1]. E. Lohmuller, B. Thaidigsmann, M. Pospischil, U. Jager, S. Mack, J. Specht, J. Nekarda, M.Retzlaff, A. Krieg, F. Clement, A. Wolf, D. Biro, IEEE Electron Device Lett., 32 (2011) 1719

[2]. B. Thaidigsmann, A. Drews, T. Fellmeth, P. Saint-Cast, A. Wolf, F. Clement, R.Preu, D. Biro,IEEE J. Photovolt., 2 (2012) 109.

[3]. F. Kiefer, C. Ulzhöfer, T. Brendemühl, N.-P.Harder, R. Brendel, V. Mertens, S. Bordihn, C.Peters, JW. Müller, IEEE J. Photovolt., 1 (2011) 49 .

[4]. D. Kray, J. Dicker, D. Osswald, A. Leimenstoll, S.W.Glunz, W. Zimmermann, K.-H.Tentscher, G. Strobl, 3rd WCPEC., (2003) 11.

[5]. J. Renshaw, A. Rohatgi, 37th IEEE PVSC., (2011) 2924.

[6]. F. J. Castano, D. Morecroft, M. Cascant, H. Yuste, M. W. P. E. Lamers, A. A. Mewe, I. G.Romijn,E. E. Bende, Y. Komatsu, A. W. Weeber, I. Cesar, 37th IEEE PVSC., (2011) 1038.

[7]. T. Boscke, R. Hellriegel, T. Wutherich, L. Bornschein, A. Helbig, R. Carl, M. Dupke, D.Stichtenoth, T. Aichele, R. Jesswein, T. Roth, C. Schollhorn, T. Geppert, A. Grohe, J. Lossen, H.-J. Krokoszinski, 37th IEEE PVSC., (2011) 3663.

[8]. P. Ortega, G. Lopez, A. Orpella, I. Martin, M. Colina, C. Voz, S. Bermejo, J. Puigdollers, M.Garcia, R. Alcubilla, 8th Spanish CDE' (2011) 1 .

[9]. M. Jeon, J. Lee, S. Kim, W. Lee, E. Cho. Mater.Sci. Eng., B., 176(2011)1285.

[10]. T. Janssens, N.E. Posthuma, B.J. Pawlak, E. Rosseel, J. Poortmans, 25th EUPVSEC , (2010)1179.

[11]. T. Markvart, L. Castaner, Practical handbook of photovoltaics fundamentals and applications,Elsevier, Oxford, 2006

[12]. B. Parida, S. Iniyan, R. Goic, A review of solar photovoltaic technologies, Renewable and Sustainable Energy Reviews 15/3 (2011) 1625-1636.

[13]. R. Ciach, J. elazny, Photovoltaic material and technology,Foundation of development inmaterial science, Cracow, 2005(in Polish).

[14]. C. Dunsky, Laser processes in PV manufacturing, An update, Industrial Laser Solutions for Manufacturing.Technology and Applications of Lasers for Industrial Materials Processing, 2012.

[15]. B. I. Adamu ${ }^{1 *}$, G.Babaji ${ }^{2}$, A.S. Gidado ${ }^{2}$, I. M. Musa ${ }^{1}$, S. S. Abdullahi ${ }^{1}$ and H.Y. Hafeez ${ }^{1}$, (2015).Influence of Thickness on Titanium Dioxide - Roselle (Zobo) Dye Sensitized Solar Cell,International Journal of Pure \& Applied Sciences, Published by Oxford Research and Publications Vol.6 (2), 71-78, January, 2016

[16]. Agilent. IV and CV Characterization Cells Using the B1500A. Application NoteB1500-14,(Cv). Retrieved from http://cp.literature.agilent,com/litweb/pdf/5990-4428EN.pdf.(2014).s 